\title{
Research on Public Art Intervention in Rural Public Space Transformation
}

\author{
Wei Zhou \\ Wuhan University of Science and Technology \\ Wuhan, China
}

\author{
Jue Wang \\ Wuhan University of Science and Technology \\ Wuhan, China
}

\begin{abstract}
With the introduction of a series of national policies, rural revitalization has become a hot issue of concern to all. In the process of rural revitalization, the creation of rural public space is the most important thing. It is related to all aspects of villagers' production and life. The status quo of the rural areas is: indifference in interpersonal relationships, gradual dilution of public awareness, and loss of young labor. These issues have become the focus of public art intervention and the focus of transformation. As an important way to dialogue with the city and people, public art will inject a lot of energies and vitality into the construction of the new countryside and enhance the charm of the countryside. Through this kind of intervention, transformation, interaction, and exchange, more villagers will pay attention to art, feel art, and their quality and taste will be enhanced. Based on the theoretical research, this paper takes the public art intervention of Xiongjia Wonderland Village in Huangshi City as an example. Through the field research and investigation, the local public space was redesigned. In response to the status quo problem, the design concept was concretely implemented in practice, which made up for the loopholes and shortcomings of local village construction, and also opened up new ideas for rural revitalization and sustainable development.
\end{abstract}

Keywords-public art; rural public space; intervention; transformation research

\section{INTRODUCTION}

The reform and opening up has brought about rapid development of China's urban construction, but the construction of vast rural areas has been ignored. Today, the rural construction in China is mainly focused on the protection of historical and cultural resources and the construction of rural buildings, but less on the research, exploration and attention of the public space environment, just staying in the beautification of the environment. On the basis of establishing rural culture, environment and folk customs, public art can bring a new living environment for the creation of rural public space, and solve the problems in the rural public space of countries. This paper not only from the perspective of a designer, but also from the perspective of artists and the public to consider how to transform the rural public space, how to use the combination of theoretical knowledge of public art and rural construction to improve the rural environment and the spiritual life and aesthetic level of the villagers, finally achieving rural revitalization.

\section{The ConcePt AND PRESENT Situation ANALysis of RURAL PUBLIC SPACE}

\section{A. The Concept of Rural Public Space}

"Public space" refers to the space that the public is free to enter and exit and it opens to everyone. Its significance is not only a concept of geography, but more importantly, lies that people who enter the space can participate, widely communicate, interact, conduct daily interactions, and participate in public affairs in the places. The "rural public space" is a concept unique to the village and it consists of two aspects: the one is that it is a kind of public place where people in the community can freely enter and exchange ideas. For example, the stage, temples, ancestral halls, fairs, wells, riversides, etc. in Chinese rural settlement, where people can freely gather, exchange their opinions, ideas, and disseminate various news. The other one refers to some institutionalized organizations and activities forms that are common in the community, such as organizations, cultural activities, and weddings and funerals in the villages. People can also communicate and interact with each other. The rural public space not only bears the functions of production, life, commerce, religion, leisure and entertainment, but also is the most easily recognized and memorable part of people, and it is also the unique charm of the country.

\section{B. The Characteristics of Rural Public Space}

In recent years, with the prosperity of social life, people began to return to the countryside. The simple nature of the country, the faintness and leisure make people slow down from the fast city rhythm, while the countryside also carries the memories and feelings of generations. The public space in the countryside is the space for returning to living: threshing ground, ancient trees, old wells, courtyards, stage, etc. are the traditional existence ways of rural public space, including production, life, faith, communication, morality, etc., which are closely related to people's life and embody the true nature of life. At the same time, the rural public space is also dominated by the ideas of the ancestors, and does not contain any artificial creation. It is built up by relying on the peasants' "labor work" and represents a sort of harmonious beauty characterized with the interdependence and mutual adaptation between people and nature. This beauty is a masterpiece of the peasants, who deeply love their lands by means of acquired knowledge and skills with the lowest energy consumption to 
meet the needs of production and life. This kind of beauty is a natural beauty without artificial carving. Different from the high buildings of the city, it is the beauty of baptism and precipitation in the long history. As a primary form of human gathering, the countryside has its unique and rich spatial form, a dynamic spatial layout, and an architectural form of pleasant size, reflecting its unique charm distinguished from the city.

\section{Problems Existing in Rural Public Space}

1) The decline of public space: From the founding of New China to the reform and opening up, with the advancement of modernization, industrialization, and urbanization, the functions of some rural public spaces have weakened and disappeared, further resulting in indifferent rural interpersonal relationships, shrinking rural emotional ties, lack of regional identity sense among villagers, backward infrastructure, the loss of rural capital stocks and the low self-management ability of villages. All these situations are generally led by the lifestyles of rural areas, the influence and impact of people's thoughts, the penetration of market economy, the decline and backwardness of agricultural production, the large number of young people going out to work, and the frequent flow of people, the alienation of "village customs", "hollow village" and other factors. The original villages with rich vitality and full of deep feelings have begun to fade out of people's attention and no one cares.

2) Homogeneity of public space: The development of urban and rural integration brings not only the development of the countryside, but also the homogenization of the rural public space. Today's new rural construction takes urban construction as a reference, and the planning, layout, and construction of the city are hard-wired to the rural construction, destroying the original layout, function, and characteristics of the rural public space, ignoring the local style that the village originally had. The lack of regionality in rural areas makes the form of expression single, which leads to the similarity of the layout and characteristics of rural space in today's construction and lack of the local customs and conditions. So, the new country construction fails to play a role in rural building to a certain extent.

3) Lack of interactivity in public space: The changes in the rural system and industrial institutions have caused the disintegration of the production method of the cooperative system, which has also led to the peasant's collective consciousness becoming weaker and weaker, made them lack the awareness of participating in public activities, and tend to communicate with individuals and families as a group. The bastion of the concept was further disintegrated, and the traditional ethics and patriarchal consciousness disappeared, making the village lose the cultural unity and uniformity and rendering the cultural identity and cultural self-confidence decline.

\section{Public ART InTERVENTION IN RURAl PUblic SPACE TRANSFORMATION}

\section{A. Intervention Background}

Since the 18th National Congress of the Communist Party of China, the Party Central Committee with General Secretary $\mathrm{Xi}$ Jinping as the core has regarded the insistence on solving the problems of agriculture, rural areas and peasants as the key of building a new socialist countryside. General Secretary Xi Jinping proposed the "Village Revitalization Strategy" in the report of the 19th National Congress. The proposal of this strategy has pointed out the direction for the deepening of rural spiritual civilization construction and the transformation of rural public space. "The rural areas must retain green mountains and green hills, and tie the homesickness", which not only expresses the yearning for a better life, but also implies a virtuous cycle of economy and ecology and means a harmonious balance between man and nature. As a new way to practice the national cultural development strategy, public art design is trying to turn the national cultural concept into a cultural reality to become an important mode to lead the people to live a better life: transforming the public space of the local village through the intervention of public art; rebuilding rural characteristic culture; improving infrastructure conditions building a spatial exchange platform with public art; enhancing rural cohesiveness and villagers' pride; promoting local cultural exchanges and interactions; attracting the return of capital and manpower, and urging the public to actively participate in construction.

\section{B. Intervention Advantage}

As the largest developing country in the world, rural construction has always been an important basic construction of China. The contemporary new rural construction is only a spatial restoration of the countryside, and it is always the same. It fails to understand and interpret according to the local cultural background and traditional customs, and to create, express and interact with each other on the basis of restoration.

The transformation of public space and the revitalization of the countryside are tasks that cannot be delayed. Public art refers to the art creation and design in public spaces. The involvement of public art is not only the ornaments and works of art, and it also considers and treats the public environment from the perspective of art, so as to optimize the living conditions and its own situation. It is the necessary and reasonable and natural composition of real existence of its own people, the occurrence of its affairs, enabling a harmonious interaction between man and nature. At the same time, the intervention design of public art in the countryside can positively affect the peasants, improve the aesthetic level of them, infiltrate the traditional culture, and improve the quality of life and happiness; the intervention of public art is an interpretation and expression of rural culture from different aspects, carrying historical information. It enables the public to learn more about the past through public art, including background, historical events, deeds, ideology and culture, so that they will pay more attention to regional culture, historical development, humanistic feelings, etc., and can reshape the local traditional civilization and cultural ecology. Public art is 
essentially a medium that can spread traditional rural culture, shape customs with local characteristics, attract people into the countryside through the integration of resources to understand rural culture and experience local customs. So, a bridge between the countryside and people will be built and the new path of rural revitalization will be successfully explored.

\section{CASE ANAlysis of PUblic ART TRANSFORMATION IN XIONGJIA WONDERLAND VILLAGE}

\section{A. Background Analysis}

The development of contemporary Chinese public art is related to the development of urban construction. But the development of the city has brought about a series of problems, such as the aging of the countryside, slow economic development, low per capita income, and backward infrastructure. As a result, urban and rural development gradually formed a large gap. With the introduction of the government's "beautiful rural construction" and "rural revitalization" policies, it has brought opportunities for the development of rural China.

Xiongjia Wonderland Village in Tieshan District of Huangshi City has some problems, such as slow economic development, low per capita income, single source of economy, serious loss of young labor force, and lagging local cultural development. The above problems have led to backward development of rural areas, and the non-effective integration of ecological environment and natural resources. How to intervene public art into rural public space, integrate local natural resources and traditional cultural resources to create a public space in line with local characteristics, and greatly promote the development of local rural economy is the problem faced by the author and his team colleagues.

\section{B. Intervention and Transformation Methods}

1) Step-by-step principle: The involvement of public art is gradual, not at a glance. Each village has its own characteristics and regional culture. It requires a long-term intervention process. During this period, it needs to receive feedback and accumulation, from small to large, from shallow to deep, following the principle of gradual and orderly progress. China has a vast territory and diverse ecological landscapes and there are large different village looks in different areas. In the face of differences in the geographical, cultural, topographical, and spatial structures of different villages, the intervention of public art needs to be based on the actual situation at the time, combined with different transformation needs and priorities, and then advances. In the early stage, research planning, planning and design, the grasp of diversity, otherness and regionality of the village are all indispensable. It is necessary to make sufficient preliminary preparations to build a suitable spatial structure and layout.

When using public art to transform the space of Xiongjia Wonderland Village, it's important to carry out sufficient research work in the local area firstly, integrate into the lives of local residents to experience their life and production methods and to tap the spirit and pursuit of them, and then, guide villagers to participate in the reconstruction with their favorite ways. This process enables designers and villagers to interact well, forming a "feedback" mechanism, and making public art involvement more far-reaching and lasting.

2) The principle of public participation: The involvement of public art requires public participation. The involvement of public art in the transformation of rural public space is an innovative measure. It requires more people to participate in it. Under the background of understanding the characteristics of the local situation, it's better to fully express the understanding and ideas about rural space, and produce different exchange sparks to bring different expressions and presentation techniques. At the same time, the guidance of public art to the local people to participate in the whole process can infiltrate the new ideas into the relatively backward and occluded thoughts of the local people, which can not only improve their aesthetic level, broaden their horizons, but also promote their collective sense of honor and centripetal force and the villagers' awareness of participating in public utilities can also been strengthened, which enable the villagers to participate spontaneously in the transformation of public space and better promote this process in the experience and understanding of art. In response, infinite vitality and possibilities for the transformation of public art will be created.

At the same time, the principle of public participation can fully understand the true ideas and wishes of the villagers and strengthen the relationship between the participants and the public space. When intervening in the public space transformation of Xiongjia Wonderland Village, different design techniques of public art in the space have been used to attract more villagers to participate and pay attention, and at the same time, it has become part of the natural environment, making the combination of the natural environment, public space and art, which not only solves the contradiction between professional requirements and public opinion, but also enhances the feelings with the villagers, improves the weakening trend of the villagers' feelings, and enhances the villagers' sense of identity and pride for the village community by the completed results of joint participation.

3) The principle of local conditions: The so-called local conditions are the traditional view of nature, "harmony between man and nature", which means the organic coordination between man and nature. Any public space is in a specific environment, and there are inextricable relationships with the surrounding environment. The intervention of public art is limited to a large extent to the factors such as form, landform, topography and economy and so on. And these objective environmental factors will also bring unexpected design effects and breakthroughs to public art intervention.

Xiongjia Wonderland Village is located in the west of Huangshi National Mine Park and it is adjacent to the Buddhist tourist resort of Dongfang Mountain in the east with more than 460 meters above sea level. Known as the fairyland and the paradise, the whole village is surrounded by mountains with 
layers of peaks and beautiful scenery. There is a 30,000square-meter Dongfang Tianchi in the village, like a mirror inlaid in the pines and bamboos. In more than 3,000 acres of mountain forests, there are centuries-old acacia trees and centuries-old camphor trees, which are lush and radiant; it is a fertile ground for humanity with unique human landscape, numerous historical sites and monuments. In the face of these characteristic natural landscapes, the design scheme subtly takes and retains them, combining the beauty of natural landscapes with advanced technological means. Take the 400meter cement slope of the road that must be passed through on the way to get into village as an example: the traditional embossed murals are bases with physical objects, sound and light, and so on, which breaks the rigidity of the original 100meter slope in space, visual and color and breaks the original monotonous wall with various artistic shapes. The modern technologies, such as optoelectronics are used in the scene gallery, combining murals, sculptures with real-time interactions and installation art, which makes viewing, participation and leisure a whole. And finally, the effect of the sentiment in the scenery, the combination of people and scenery will be achieved.

4) Principle of sustainable development: The involvement of public art helps to optimize the transformation of public space structure. By organically combining with industry and preserving the ecological background, it assists to improve the quality of rural construction, introduce new formats and enhance and innovate the development of business models, finally implementing sustainable development.

The scenic area of Xiongjia Wonderland Village has many mountains, many trees and many flowers. Through the analysis of the natural environment, "green mountains and waters tie the nostalgia" has been set as the space theme. In the village's landscape corridor, a century-old acacia tree is set to restore the real scene, and there are four major areas with the theme of "spring", "summer", "autumn" and "winter". The commercial spaces are established separately in the design of the four regions, such as schools, commercial, handicrafts, small squares and so on. The rescue and repair of old dangerous buildings, and the transformation of them help to achieve the sustainable development of villagers' economic income and the rural ecological environment. With green and ecology as the main elements, the Xiongjia Wonderland Village has been seeking harmony between man and nature and the countryside.

\section{CONCLUSION}

With regard to the involvement of public art in rural public spaces, it is necessary to realize its publicity so that it can be accepted by local villagers and it is essential to shape the characteristics of space values recognized by farmers. At the same time of intervention, the spirit of the public place, the characteristics of the local environment, the appearance and the sublimation of the context should be created. The unique geographical significance of the rural space should be combined with the meaning of the place, and the design resources should be found in the combination to extract the symbols with regional characteristics. Based on these regional features, the local environment, greening, traditional customs and design concepts should be fully integrated into design theory so as to make a design of an environmental style element that meet various needs of local villagers and visitors. The involvement research of public art in the rural public space is not only an in-depth study of public art design, but also an important means of driving rural economic development and realizing the rural revitalization strategy.

\section{REFERENCES}

[1] Qin Feng. Feasibility Study of Public Art Intervention in Rural Greenway Construction[J].Chinese Horticultural Digest,2017,33(06):141-144. 秦凤.乡村绿道建设中公共艺术介入的 可行性探究[J].中国园艺文摘, 2017, 33(06):141-144.

[2] Liu Can. The Application of Contemporary Public Art in the Reconstruction of Rural Public Space Landscape[D].Beijing Institute Of Fashion Technology,2018. 刘灿. 当代公共艺术在乡村公共空间景观 改造中的应用[D].北京服装学院,2018.

[3] Wang Donghui. The Status Quo, Problems and Countermeasures of Chinese Contemporary Public Art[D].Chinese National Academy of Arts, 2012. 王东辉. 中国当代公共艺术的现状、问题与对策[D].中国 艺术研究院,2012.

[4] Song Xiaoqing. Constructing the Spirit of the Place--the Application Strategy of Public Art in the Construction of New Rural Communities in Zhejiang[J]Xiandai Horticulture,2018(09):85-86. 宋晓青.构建场所 精神——公共艺术在浙江新农村社区建设的应用策略[J].现代园艺, 2018(09):85-86. 